\title{
COMPARISON OF THREE NATURE TRAILS IN KANNELIYA MAB RESERVE FOR NATURE BASED TOURISM WITH SPECIAL REFERENCE TO BIODIVERSITY.
}

\author{
H M S D H Hthursingha and D M S H K Ranasinghe \\ Department of Forestry \& Environmental Sciences, \\ University of Sri Jayewardenepura
}

The Kanneliya Forest Reserve and Nakiyadeniya Proposed Reserve in Galle District and Dediyagala Forest Reserve in Matara District form continuous block of natural forest (KDN Forest complex) covering 11,146 ha in the south-west lowland hills. The KDN forest complex was logged by the Ceylon Plywoods Corporation between 1968 and 1988 . However, Kanneliya MAB Reserve, one of the immaculate tropical rainforests, which covers 5305 ha of area, blended with majestic features is an ideal rain forest for recreation. Its close proximity to other recreational sites adds to its overall recreational value. Conservation management plan for KDN Complex (1995) also had identified Kanneliya as a probable site for nature based tourism.

This study focused on evaluating the potential of the forest reserve for nature based tourism. The faunal biodiversity of the reserve useful for nature-based tourism was enumerated in 3 welldefined nature trails, which are already present. Three visits were made along these trails on three successive dates. In each trail 10 inward and out ward journeys were made taking random time gaps. During these visits all the faunal species encountered were recorded. All the tree species and herbs along these trails at visible range were also recorded. The study covered one entire season intended to capture migratory animals also.

Results showed in Nature trail up to Narangas ella to Anagimala ella (NT1), 79 tree species were counted with $63 \%$ of endemic species and 4 threatened species. In the Nature trail of Kabbale kanda $300 \mathrm{~m}$ from MSL (NT2) 78 tree species were recorded with $67.9 \%$ endemic species and 6 threatened species. Nature trail 3 in "Mola kanda" (Highest point 250m from MSL) NT3 tree species were recorded with $65.6 \%$ endemic species and 4 threatened species

At NTI 53 bird species were recorded among them 8 were endemic and 7 were winter visitors, 31 butterfly species with 9 endemic, 9 reptile species with 3 endemic, 3 amphibians with 1 endemic, 4 mammal species with 3 endemic and 5 fish species with 4 endemic.

NT2 recorded 45 bird species with 6 endemic and 8 winter visitors, 30 butterfly species with 09 endemic species, 8 reptile species with 2 endemic, 5 amphibians with 4 endemic, 5 mammals with 2 endemic and 6 fish species with 5 endemic.

At NT3 46 bird species were recorded with 5 endemic and 7 winter visitors, 28 butterfly species 08 endemic, 6 reptile species with $l$ endemic, 2 amphibians with 1 endemic, 5 mammals with 1 endemic and 19 fish species with 12 endemic

NT2 had the highest floristic diversity followed by NT1 and NT3. In terms of faunal diversity NT1 holds the highest value followed by NI2 and NT3. Birds and Butterflies showed the highest probability in NT1 followed by NT2. However, NT3 showed remarkably weakest probability. Therefore it can be concluded by way of observing biodiversity NT1 \& NT2 have the highest potential.

Proceedings of the Ninth Annual Forestry and Environment Symposium 2003 of the Department of Forestry and Environmental Science, University of Sri Jayewardenepura, Sri Lanka 